\title{
Jan Miernowski, La beauté de la haine. Essais de misologie littéraire
}

\section{Riccardo Benedettini}

\section{(e) OpenEdition \\ 1 Journals}

\section{Edizione digitale}

URL: http://journals.openedition.org/studifrancesi/1688

DOI: 10.4000/studifrancesi. 1688

ISSN: 2421-5856

\section{Editore}

Rosenberg \& Sellier

\section{Edizione cartacea}

Data di pubblicazione: 1 novembre 2014

Paginazione: 657

ISSN: 0039-2944

\section{Notizia bibliografica digitale}

Riccardo Benedettini, « Jan Miernowski, La beauté de la haine. Essais de misologie littéraire », Studi

Francesi [Online], 174 (LVIII | III) | 2014, online dal 01 novembre 2014, consultato il 18 septembre 2020. URL : http://journals.openedition.org/studifrancesi/1688; DOI : https://doi.org/10.4000/studifrancesi. 1688

Questo documento è stato generato automaticamente il 18 settembre 2020.

\section{(c)}

Studi Francesi è distribuita con Licenza Creative Commons Attribuzione - Non commerciale - Non opere derivate 4.0 Internazionale. 


\title{
Jan Miernowski, La beauté de la haine. Essais de misologie littéraire
}

\author{
Riccardo Benedettini
}

\section{NOTIZIA}

JAN MIERNOWSKI, La beauté de la haine. Essais de misologie littéraire, Genève, Droz, 2014, («Histoire des idées et critique littéraire», 473), pp. 280.

Il presente volume si propone il compito di studiare la «beauté de la haine» - dove, con il termine «beauté», si rinvia alla «visée esthétique» (p. 17) dell'analisi - attraverso un percorso che, dal XVI al XXI secolo, vuole abbracciare autori e testi (poesie, pamphlets, opere teatrali e romanzesche) di lingua francese, scelti per la loro rappresentatività. Come si legge nell'introduzione, «Haïr pour la beauté de la chose même» (pp. 9-20), MIERNOWSKI muove dall'opposizione aristotelica tra l'odio e la collera - distinzione poi rivista da Cicerone in termini di odio quale "colère invétérée» (p. 15) - per meglio delineare l'estetica precisa attraverso la quale l'odio si fa discorso in un'opera d'arte. A questo fine, l'A. inquadra il vasto materiale raccolto in quattro tappe: «La haine poétique et rhétorique» (pp. 21-74), «La haine tragique» (pp. 75-125), «La haine littéraire» (pp. 127-166), «La haine qui se veut sublime» (pp. 167-232). Miernowski inizia la sua indagine chiedendosi come possa essere presente l'odio in una cultura così erocentrica quale quella del Rinascimento; egli designa nel contr'amour non tanto l'alternanza di Eros e di Anteros, quanto la sostituzione dell'odio all'amore. Questa posizione si manifesta particolarmente attraverso il frequente ricorso ai testi di Jodelle e a quelli dei pamphlétaires radicali dei tempi delle guerre di religione: la lingua di Pibrac, di Burin o di Charpentier ricorda, scrive l'A., la «novlangue totalitaire du $\mathrm{xx}^{\mathrm{e}}$ siècle» (p. 55), in quanto «langue nouvelle de la réalité nouvelle» (ivi). L'analisi di siffatta «violence verbale» (p. 73) fa da tramite con i Traités des passions del secolo successivo: tracciato un bilancio dell'odio tragico seicentesco, l'A. consacra la propria attenzione alla Rodogune di Corneille, dove la figura di Cleopatra concepisce «la haine 
comme une valeur morale» (p. 99), e alla Thébaïde di Racine, tragedia anch'essa definita come «un festival de haine» (p. 79). Nella terza tappa del volume Miernowski si concentra poi su Rousseau, autore e personaggio, che rompe con la doxa dei Philosophes e sembra avere quale obiettivo estetico quello di «trouver une forme d'écriture qui soit libre du risque de la haine» (p. 152). Come arrivarci? Costruendo, suggerisce l'A., «des personnages insensibles et émotionnellement indifférents» (ivi). Circa l'ultima parte del lavoro, la misologia di Céline è introdotta da rinvii a Baudelaire e a Lautréamont. Se una costante resta - «la haine de l'homme et de Celui qui le créa» (p. 166) -, è con Céline-Bardamu, nonché con l'autore degli écrits polémiques (cfr. ed. di R. Tettamanzi, éditions 8, 2012; e «Studi francesi», 173) e di Mort à crédit, che la scrittura sarà «quoiqu'il arrive, mue, propulsée par la haine» (p. 180), con tratti che saranno poi ereditati dalla letteratura misologica contemporanea, come si evidenzia nell'epilogo, «Au-delà de la haine» (pp. 233-253), in una prospettiva in cui l'odio non è solo forza distruttrice ma principio di creazione artistica. Chiudono il volume la «Bibliographie» (pp. 255-271) e l'«Index» (pp. 273-278). 